\title{
A NEW COLORIMETRIC MICROESTIMATION OF SUGAR IN BLOOD AND BIOLOGICAL FLUIDS
}

\author{
BY \\ I. ST. LORANT \\ From the Pathological Department, Queens Park Hospital, Blackburn
}

(RECEIVED FOR PUBLICATION MAY 4, 1956)

Although of the many colorimetric microestimations of sugar the Folin and Wu method (1920) has remained in most widespread use in clinical laboratory practice, the still increasing number of modifications continue to draw attention to several inherent weaknesses of the method which have not yet been eliminated, one of which is the instability of the colour solution.

To avoid these drawbacks a more robust and reliable method has been developed, based on the oxidation of the sugar by potassium ferricyanide, and colorimetric determination of the ferrocyanide formed by means of the yellowish-brown solution of its molybdenum compound.

Hagedorn and Jensen (1923) had attempted to develop a colorimetric method using the potassium ferricyanide oxidation but met with no success. Folin and Malmros (1929) and later Milton (1942) similarly employed this principle, but their methods failed to gain general recognition, again mainly because of the unsuitable nature of their colour solution for colorimetry.

The applicability of the molybdenum ferrocyanide salt to colorimetric measurements was investigated in a series of experiments. It appeared that if the customary concentrated phosphoric acid is replaced by a correspondingly concentrated solution of oxalic acid to act as solvent, and trichloroacetic acid is used to reach the required acidity, molybdenum ferrocyanide will yield an excellent colour. This not only obeys Beer's law well but it also has such good keeping qualities that with very few precautions its intensity can be maintained constant for many hours or even for days.

All solutions in the method described are easily prepared and they remain unchanged for years.

\section{Experimental}

Reagents.-The following are required:

(1) Isotonic Sodium Sulphate Solution.-For this reagent $13.2 \mathrm{~g}$. $\mathrm{Na}_{2} \mathrm{SO}_{4}$ anhydrous A.R. is dissolved in $1,000 \mathrm{ml}$. water.
(2) Aluminium Sulphate Solution.-For this reagent 7.5 g. $\mathrm{Al}_{2}\left(\mathrm{SO}_{4}\right)_{3}, 18 \mathrm{H}_{2} \mathrm{O}$ A.R. is dissolved in $100 \mathrm{ml}$. water.

(3) Sodium Tungstate Solution.-A quantity, $10.0 \mathrm{~g}$. $\mathrm{Na}_{2} \mathrm{WO}_{4}, 2 \mathrm{H}_{2} \mathrm{O}$ A.R., is dissolved in $100 \mathrm{ml}$. water.

(4) Potassium Ferricyanide Solution.-To make this solution, $1.80 \mathrm{~g} . \mathrm{K}_{3} \mathrm{Fe}(\mathrm{CN})_{6}$ A.R. is weighed on a watch- 3 glass and dissolved in $1,000 \mathrm{ml}$. water. The solution is filtered through a plug of glass wool which has been $\vec{\theta}$ washed previously with distilled water and allowed to $\mathcal{G}$ drain. The filtrate, which serves as stock solution, is . stored in a brown bottle preferably in the cold. Smaller quantities of this solution may be kept on the bench.

(5) $0.1 \mathrm{~N}$-Sodium Carbonate Solution A.R.

(6) Molybdate-Oxalic Acid Reagent.-For this reagent, 120 g. $\mathrm{Na}_{2} \mathrm{MoO}_{4}, 2 \mathrm{H}_{2} \mathrm{O}$ (purest quality) and $50 \mathrm{~g}$. $\stackrel{\mathbb{2}}{\AA}$ $(\mathrm{COCH})_{2} 2 \mathrm{H}_{2} \mathrm{O}$ A.R. are dissolved in water, and the solution made up to 1 litre. Smaller quantities of this solution may be kept on the bench for immediate use. With time flakes tend to separate, but they do not interfere with further analysis. They can be removed by filtration or their formation inhibited by storage in polythene vessels.

(7) Trichloroacetic Acid Solution.-Trichloroacetic acid, $100 \mathrm{~g}$., is dissolved in $400 \mathrm{ml}$. water in a measuring cylinder.

(8) Standard Glucose Solution.-Glucose A.R., $250 \mathrm{mg}$., is dissolved in an isotonic solution of sodium sulphate saturated with benzoic acid, and made up to $100 \mathrm{ml}$. in $\frac{D}{2}$ a volumetric flask with the same solution. Of this stock solution, $2 \mathrm{ml}$. in another $100 \mathrm{ml}$. volumetric flask $N$ made up to the mark with the sodium sulphate-benzoic क acid solution serves as standard and contains $50 \mu \mathrm{g}$. $\tilde{o}$ glucose per $\mathrm{ml}$.

(9) Diluting Solution.-The following are mixed:

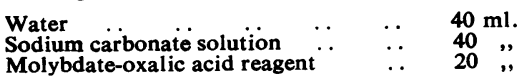

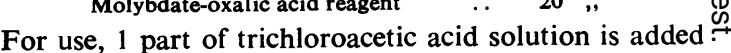
to 5 parts of this mixture in a graduated cylinder.

\section{Procedure}

Isotonic sodium sulphate, $3.5 \mathrm{ml}$., and $0.2 \mathrm{ml}$. aluminium sulphate solution are pipetted into a centrifuge $\frac{\sigma}{\sigma}$ tube, and $0.1 \mathrm{ml}$. whole blood is added. The pipette is carefully washed out with the contents of the tube. 
Then $0.2 \mathrm{ml}$. sodium tungstate solution is introduced and the contents of the tube gently mixed. The tube is centrifuged and $2 \mathrm{ml}$. of the clear supernatant fluid is pipetted into a $20-25 \mathrm{ml}$. test tube. Two other test tubes are prepared, one containing exactly $2 \mathrm{ml}$. of the standard glucose solution and the other $2 \mathrm{ml}$. sodium sulphate solution to be used as a blank.

Potassium ferricyanide, $5 \mathrm{ml}$., and $5 \mathrm{ml}$. sodium carbonate solution are added to all tubes, which are then placed in a gently boiling water-bath for 15 minutes. The heating on the bath can be prolonged up to 30 minutes. After cooling for a few minutes $2.5 \mathrm{ml}$. molybdate-oxalic acid reagent and $2.5 \mathrm{ml}$. chloroacetic acid solution are added, and the solutions are mixed.

Direct sunlight is to be avoided during the entire procedure. Should colorimetry be delayed after the development of the colour, or if it is required to check the colour solutions later, the test tubes should be protected from strong light. They can be stored in a drawer or covered with a cardboard box. In cases of very high sugar concentrations, above $400 \mathrm{mg} . / 100 \mathrm{ml}$., the coloured solution is diluted before measurement. Of the coloured solution, $5 \mathrm{ml}$. is diluted two or three times with the diluting reagent and the resulting coloration estimated. The colorimetry can take place immediately after the colour has formed. If a photoelectric absorptiometer is employed it is advantageous to use an Ilford 303 blue filter.

\section{Calculation}

To calculate the sugar in undiluted colour solutions, sugar $(\mathrm{mg} . / 100 \mathrm{ml})=.200(X-B) / S-B$, where $X=$ reading of the test, $B=$ reading of the blank, $S=$ reading of the standard, and in diluted colour solutions sugar (mg./ 100 $\mathrm{ml}.)=200 \mathrm{y}(X-B) / S-B$, where $\mathrm{y}=$ degree of dilution (two- or three-fold and so on).

In practice, for purposes of zero setting the blank also may be used.

\section{Notes on the Procedure}

Aluminium tungstate as a deproteinizing agent is often useful when zinc hydroxide or copper tungstate cannot be used. It does not interfere with subsequent analysis or damage the blood corpuscles; it inhibits glycolysis for several days. It may occur, as in the case of copper salts in Folin and Wu's (1920) method, that if the centri uged precipitate is allowed to stand in contact with the supernatant liquid for a prolonged time a turbidity develops in the clear layer. The opalescence does not form in the presence of proteins but can form if for some reason the deproteinizing agents are included in the blank solution. In any case it is of no importance for further estimations.

The heating on the bath can be prolonged up to 30 minutes.

The potassium ferricyanide is sufficient for blood sugar levels higher than $1,200 \mathrm{mg}$. $/ 100 \mathrm{ml}$. to be determinable.
After the addition of the trichloroacetic acid solution the colour reaches its maximum intensity practically instantaneously and will remain so for a few hours. If after the development of colour the test tubes are protected from light, the intensity of colour will not change for many hours; afterwards a small intensification may take place, but as the blank and the standard changes concurrently the calculated results remain the same.

Under the condition described, Beer's law is very closely obeyed (Table I).

TABLE I

RESULTS

\begin{tabular}{c|c|c}
\hline \multicolumn{2}{|c|}{ Glucose ( $\mu$ g.) } & $\begin{array}{c}\text { Standard } \\
\text { Deviation } \\
(\%)\end{array}$ \\
\hline Taken & Found & -2 \\
25 & $24 \cdot 5$ & 0 \\
50 & 50 & 0 \\
100 & 100 & $+1 \cdot 6$ \\
250 & 254 & -1.25 \\
400 & 395 & -28 \\
500 & 486 & -1.7 \\
600 & 590 &
\end{tabular}

$100 \mu \mathrm{g}$. glucose corresponds to $200 \mathrm{mg}$. $/ \mathrm{ml}$. glucose in the test solution.

In Table II routine estimations of the same oxalated blood, to which varying amounts of glucose were added, are shown. The calculated results are compared with the initial values.

TABLE II

ESTIMATION OF BLOOD SUGAR WITH ADDED GLUCOSE

\begin{tabular}{|c|c|c|c|c|c|}
\hline \multirow{2}{*}{$\begin{array}{c}\text { Blood } \\
(\mathrm{ml} .)\end{array}$} & \multicolumn{2}{|c|}{$\begin{array}{c}\text { Glucose } \\
(\mu \mathrm{g} .)\end{array}$} & \multirow{2}{*}{$\begin{array}{c}\text { Recovery } \\
\text { of Added } \\
\text { Glucose } \\
(\mu \mathrm{g} .)\end{array}$} & \multirow{2}{*}{$\begin{array}{c}\text { Theoretical! } \\
(\mu \mathrm{g} .)\end{array}$} & \multirow{2}{*}{$\begin{array}{c}\text { Standard } \\
\text { Deviation } \\
(\%)\end{array}$} \\
\hline & Added & Found & & & \\
\hline $\begin{array}{l}0 \cdot 1 \\
0 \cdot 1 \\
0 \cdot 1 \\
0 \cdot 1 \\
0 \cdot 1 \\
0 \cdot 1 \\
0 \cdot 1\end{array}$ & $\begin{array}{l}\overline{25} \\
50 \\
100 \\
200 \\
300 \\
400\end{array}$ & $\begin{array}{l}102 \\
126 \\
154 \\
204 \\
290 \\
402 \\
516\end{array}$ & $\begin{array}{r}\overline{24} \\
52 \\
102 \\
188 \\
300 \\
414\end{array}$ & $\begin{array}{l}1 \overline{27} \\
152 \\
202 \\
302 \\
402 \\
502\end{array}$ & $\begin{array}{c}-0.80 \\
+1.30 \\
+1.0 \\
-4.0 \\
0 \\
+28\end{array}$ \\
\hline
\end{tabular}

$100 \mu \mathrm{g}$. glucose corresponds to $200 \mathrm{mg}$. per $100 \mathrm{ml}$. glucose solution.

\section{Summary}

The microestimation of sugar described here is based on the oxidation of sugar by potassium ferricyanide in solutions deproteinized with aluminium tungstate.

The amount of potassium ferrocyanide formed is estimated as the yellowish-brown molybdenum ferrocyanide dissolved in a solution of oxalic acid in the presence of trichloroacetic acid.

The method will estimate quantities higher than $1,200 \mathrm{mg}$. per $100 \mathrm{ml}$.

REFERENCES

Folin, O., and Malmros, H. (1929). J. biol. Chem., 83, 115. - and Wu, H. (1920). Ibid., 41, 367.

Hagedorn, H. C., and Jensen, B. N. (1923). Biochem. Z., 135, 46. Milton, R. F. (1942). Analyst, 67, 183. 